\title{
L命NTING \\ PENATAAN KAWASAN TEPIAN SUNGAI SEBAGAI RUANG TERBUKA DI MURUNG KENANGA, MARTAPURA
}

\author{
Dwi Sulistyaningsih \\ Program Studi Teknik Arsitektur Fakultas Teknik Universitas Lambung Mangkurat \\ 1610812120004@mhs.ulm.ac.id
}

Ira Mentayani

Program Studi Teknik Arsitektur Fakultas Teknik Universitas Lambung Mangkurat

ira_arch@ulm.ac.id

\begin{abstract}
ABSTRAK
Kawasan tepian sungai di Murung Kenanga berpotensi untuk dikembangkan sebagai ruang terbuka hijau tepian sungai yang dapat mempertahankan kelestarian fungsi sungai dan menjadi wadah sosialisasi masyarakat. Potensi ini belum diolah secara maksimal.Kondisi eksisting kawasan tepian sungai yang dimanfaatkan sebagai tempat tinggal dan pembuangan sehingga menyebabkan rusaknya kondisi tepian sungai. Kondisi permukiman kumuh yang berada disekitar kawasan menjadi kendala tambahan dalam penanganan kawasan ini. Oleh karena itu, kawasan ini memerlukan adanya penataan yang tepat sasaran dan memberikan dampak positif terhadap lingkungan di sekitarnya.Metode urban acupuncture dipilih dengan menjadikan kawasan tepian sungai di Murung Kenanga sebagai RTH dan titik aktivitas positif masyarakat sekitar kawasan. Prinsip penerapan urban acupuncture yang digunakan dalam titik rancangan pada kawasan ini adalah fokus target, biaya rendah, berlaku di setiap situasi, efek instan, memfasilitasi kebutuhan dan tindakan sederhana. Metode menjadi penunjang konsep environmental \& recreation waterfront yang diterapkan dengan menjadikan kawasan tepian sungai sebagai ruang terbuka yang rekreatif dan memperhatikan lingkungan. Penerapan konsep dan metode yang diterapkan melalui, 1) Peningkatan kualitas lingkungan kawasan melalui pemanfaatan potensi alam dan pengembalian fungsi sungai dengan pengembangan area tambak, penggunaan vegetasi tepian sungai dan turap ekologis 2) Pemanfaatan tepian sungai sebagai area rekreasi dengan perancangan taman bermain \& baca anak, taman santai, taman olahraga dan area kuliner 3) Memicu aktivitas positif masyarakat dengan pengadaan ruang terbuka hijau yang dilengkapi dengan fasilitas penunjang di dalamnya.

Kata kunci : Murung Kenanga, Urban Acupuncture, Environmental \& Recreation Waterfront
\end{abstract}

\begin{abstract}
Riverbanks in Murung Kenanga have the potential to be developed as green open space on the banks of a river that can maintain sustainability the function of the river and becomes a forum for community outreach. This potential has not been fully developed. The existing
\end{abstract}


condition of the river bank which is used as shelter and disposal, causing edge damage. The conditions of slums around the area become an obstacle to additional handling of this area. Therefore, this area requires the arrangement is right on target and has a positive impact on the surrounding environment. The urban acupuncture method was chosen by making the riverbank area in Murung Kenanga as an open green space and a positive activity point for the surrounding community. The principle of the application of urban acupuncture used in design points in the region is the target focus, low cost applies in every situation, instant effects, facilitating needs, and simple actions. The method supports the concept of environmental \& recreation waterfront that is applied by making the area river banks as open spaces that are creative and considerate of the environment. Application of concepts and methods applied through, 1) Quality improvement regional environment through exploiting the natural potential and returning functions rivers with the development of pond areas, the use of riverbank vegetation and ecological plaster 2) Utilization of river banks as recreation areas with designing playgrounds \& reading for children, relaxing parks, sports parks, and areas culinary 3) Triggering positive community activities by providing open space green equipped with supporting facilities therein.

Keywords: Murung Kenanga, Urban Acupuncture, Environmental \& Recreation Waterfront

\section{PENDAHULUAN}

Murung Kenanga adalah salah satu desa yang terletak di Kecamatan Martapura, Kabupaten Banjar. Daerah ini merupakan sebuah delta yang terbentuk dari aliran Sungai Martapura dan berada di pusat kota, tepatnya di belakang Pasar Batuah dan Masjid Al Karomah Martapura. Kawasan ini cukup strategis, hal ini didukung dengan akses yang dapat digunakan untuk mencapai ke kawasan ini yaitu melalui sungai dan darat. Letaknya yang diapit oleh Sungai Martapura menjadikan kehidupan masyarakatnya tidak lepas dari sungai sebagai salah satu penunjang kehidupan. Sungai bagi masyarakat Banjar sangat lekat dengan kehidupan masyarakat sehari-hari, sungai dijadikan sebagai tempat masyarakat beraktivitas seperti mengambil air, MCK,bermain memancing, memelihara ikan di tambak dan juga sebagai jalur transportasi. Aktivitas masyarakat di tepian sungai ini menjadi budaya dalam keseharian masyarakat di kawasan ini.

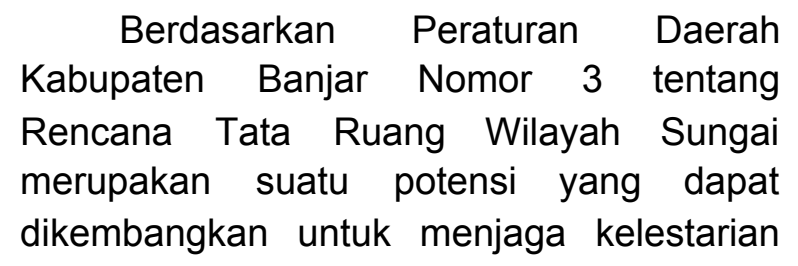

sungai dan kehidupan disekitarnya. Perda tersebut mencantumkan bahwa kawasan tepian sungai merupakan kawasan sempadan sungai yang pemanfaatannya digunakan sebagai ruang terbuka hijau dengan fungsi khusus yaitu sebagai kawasan yang berfungsi untuk mempertahankan kelestarian fungsi sungai sebagai sumber air dan sarana transportasi. Kawasan tepian sungai di Murung Kenanga merupakan tepian dari Sungai Martapura sehingga berdasarkan peraturan diatas, tepian sungai ini seharusnya diperuntukan sebagai ruang terbuka sempadan sungai.

Realita yang terjadi pada tahun 2016 berdasarkan Dokumentasi Identifikasi Lingkungan Permukiman Kumuh Perkotaan dan berdasarkan Surat Keputusan Tahun 2013 Nomor 189, Desa Murung Kenanga termasuk kedalam salah satu kawasan kumuh di Kabupaten Banjar tepatnya di Rt. 5 dan Rt.6. Desa ini menjadi prioritas penanganan kumuh dikarenakan permukimannya yang tidak teratur dengan kepadatan tinggi, kualitas bangunan serta sarana dan prasarana yang tidak memenuhi syarat. 

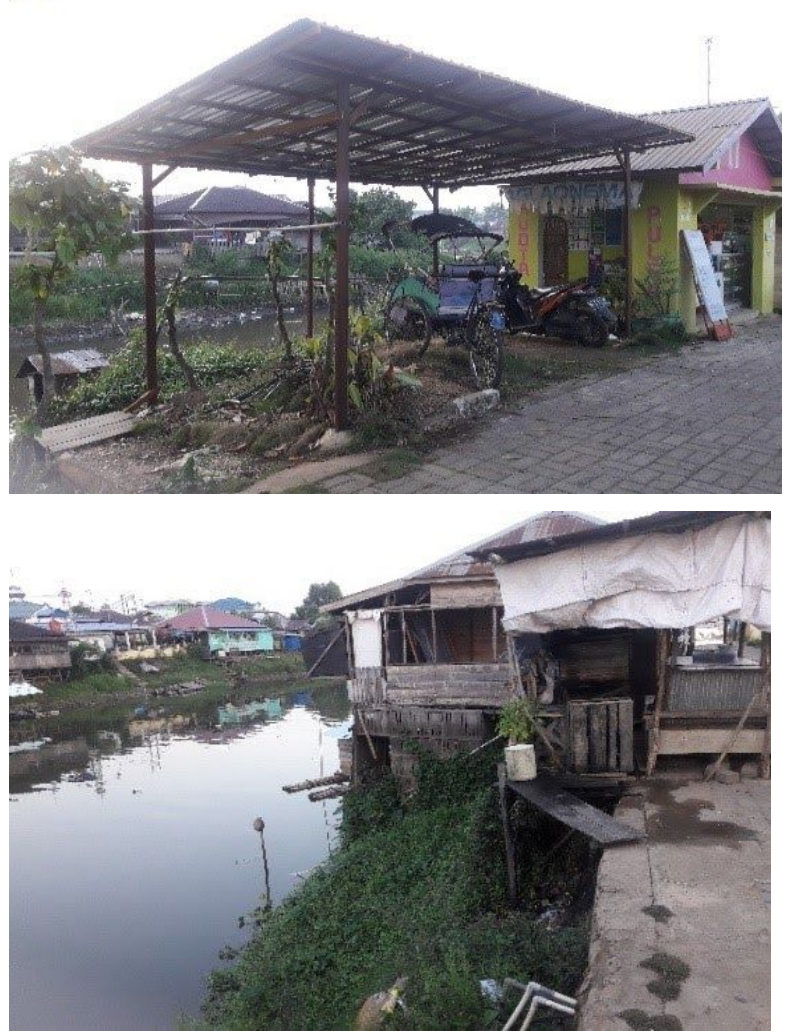

Gambar 1.Pemanfaatan Kawasan Tepian Sungai sebagai Tempat Tinggal

$\begin{array}{ccc}\text { Permukiman } & \text { yang } & \text { padat } \\ \text { menyebabkan } & \text { masyarakat } & \text { sekitar }\end{array}$

menjadikan tepian sungai sebagai tempat tinggal sehingga sungai menjadi area belakang rumah masyarakat dan menjadi tempat beraktivitas mandi, cuci, kakus serta tempat pembuangan sampah. Area tepian sungai yang seharusnya menjadi ruang penyangga ekosistem daratan dan perairan yang dapat menahan terjadinya erosi kini kehilangan fungsi ekologisnya dan berakibat pada tercemarnya sungai. Dalam hal ini diperlukan adanya pembatasan penggunaan 3 lahan agar fungsi tepian sungai tidak terganggu. Pembatasan yang dilakukan dengan melakukan penataan kawasan tepian sungai ini menjadi ruang terbuka hijau untuk meningkatkan kualitas kawasan dengan memperhatikan potensi kawasan tepian sungai. Penataan ini berbanding lurus dengan keperluan ruang bersosialisasi bagi

masyarakat sekitar. Dalam kesehariannya, masyarakat sekitar menggunakan jalan lingkungan dan teras rumah sebagai tempat mereka berkumpul atau sekedar bercengkrama. Jalan lingkungan juga dimanfaatkan oleh anak-anak di kawasan ini sebagai ruang bermain. Berdasarkan kondisi eksisting kawasan maka diperlukan adanya penataan kawasan tepian sungai di Murung Kenanga sebagai ruang terbuka hijau tepian sungai sehingga dapat mengembalikan fungsi ekologis tepian sungai dan dapat menjadi wadah bersosialisasi. Penataan kawasan tepian sungai ini diharapkan dapat meningkatkan kualitas kawasan tersebut. Penataan yang dilakukan diharapkan dapat memberikan dampak yang signifikan (sensitive effect) dalam waktu singkat. Berdasarkan potensi dan kendala di kawasan, maka pemilihan metode perancangan urban acupuncture dipilih sebagai metode dalam penataan ruang terbuka hijau yang memberikan dampak positif bagi kota dengan menyuntikkan rancangan pada titik-titik tertentu pemicu aktivitas positif sehingga dapat memberikan reaksi berantai pada kawasan disekitarnya.

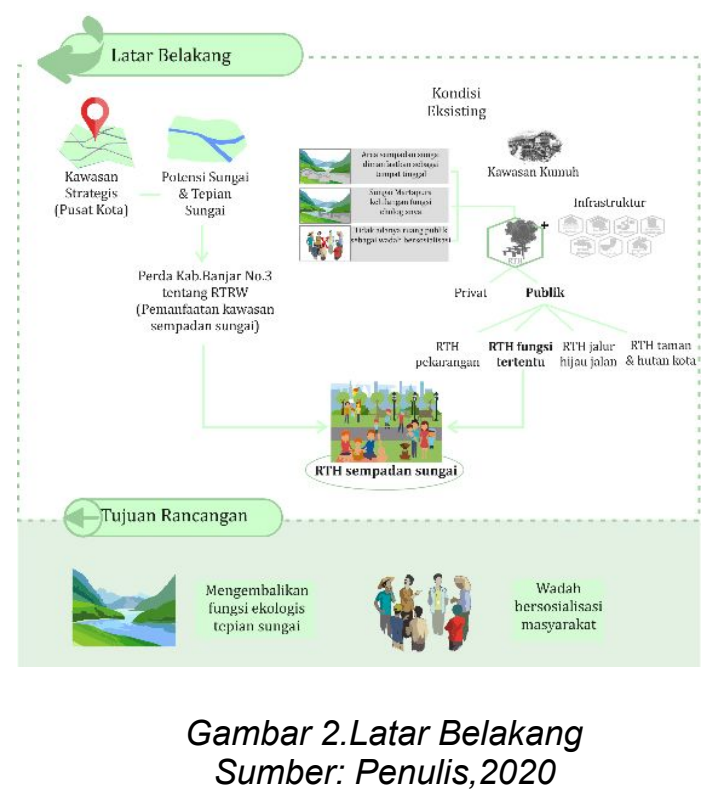




\section{PERMASALAHAN}

Berdasarkan latar belakang diatas, maka rumusan masalah yang didapatkan adalah : Bagaimana rancangan ruang terbuka hijau tepian sungai di Murung Kenanga yang dapat berfungsi sebagai wadah bersosialisasi masyarakat dan mengembalikan fungsi ekologis tepian sungai dengan menggunakan metode urban acupuncture?

\section{TINJAUAN PUSTAKA}

\section{A. Tinjauan Arsitektural}

1. Penataan Kawasan

Penataan kawasan adalah salah satu rekayasa sosial yang dilakukan di suatu wilayah secara bersamaan dengan menciptakan suatu sistem yang komprehensif terkait aktivitas yang berlangsung di kawasan tersebut, dan memperhatikan kualitas lingkungan disekitarnya. Penataan menghadirkan suatu susunan baru yang memberikan harapan kualitas kehidupan yang lebih meningkat. Proses dan hasil dari penataan kawasan merupakan bagian dari upaya dalam memberikan edukasi kepada masyarakat sekitar dan pengguna kawasan. Prinsip-prinsip dasar dalam melakukan penataan kawasan adalah sebagai berikut (Hamzens, 2013) :

1) Tujuan dari dilakukannya penataan kawasan adalah untuk meningkatkan perekonomian masyarakat setempat, mengembangkan kehidupan sosial masyarakat, dan menjaga kelestarian lingkungan.

2) Pola sistem sosial, pengembangan ekonomi masyarakat, dan penanganan lingkungan.

3) Syarat yang harus dipenuhi yaitu kesesuaian antara sumber daya alam kawasan dengan jenis kawasan yang akan ditata, adanya potensi dan dukungan pengguna kawasan terhadap pengembangan kualitas lingkungan.

4) Perencanaan yang baik diperlukan untuk menjamin penataan berjalan sesuai dengan ide gagasan.
Pemanfaatan ruang yang dilakukan secara tidak terencana dapat menyebabkan terjadinya penurunan kualitas lingkungan terutama di kawasan permukiman padat yang terletak di pusat kota dan berdekatan dengan kawasan bisnis dan industri, serta bantaran sungai. Penataan kawasan sangat penting dilakukan untuk menjaga kondisi lingkungan di kawasan tersebut dengan memperhatikan prinsip-prinsip penataan kawasan serta membuat skenario pengembangan kawasan sesuai dengan jenis dan konsep kawasan.

\section{Kawasan Tepian Sungai}

Kawasan tepian sungai merupakan salah satu bagian dari tepian air yang terletak di daratan. Kawasan tepian sungai merupakan kawasan tepian air yang memiliki beberapa nilai kelebihan dalam hal aksesibilitas dan fungsi yang strategis (Annisa, 2014). Kawasan tepian sungai merupakan kawasan tepian air yang terbentuk akibat adanya pertemuan langsung antara wilayah daratan dengan badan air sungai.Tepian sungai memiliki ciri yaitu dimanfaatkan sebagai jalur transportasi, dan sistem irigasi untuk lahan pertanian dan perkebunan yang pengembangannya menyesuaikan dengan kondisi lingkungan sekitarnya. (Ricgby, 1996).

3. Sungai Martapura di Kabupaten Banjar Sungai Martapura merupakan salah satu sungai yang terkenal di Kalimantan Selatan. Sungai ini mengalir dari hulu di Kabupaten Banjar menuju hilir yang terletak di Kota Banjarmasin. Sungai ini membentang dengan panjang $36.566 \mathrm{~m}$. Sungai ini merupakan sungai tidak bertanggul yang terletak di kawasan perkotaan. Masyarakat memanfaatkan sungai dalam kegiatan sehari-hari seperti mandi, mencuci, transportasi, memancing, dan lain-lain. Sungai bagi masyarakat Banjar memiliki banyak peran dan fungsi seperti sebagai sumber air, jalur transportasi, dan sumber mata pencaharian yang tergambar melalui aktivitas budaya kehidupan sungai 
(Mentayani, 2019). Berdasarkan Peraturan Daerah Kabupaten Banjar Nomor 3 Tahun 2013 tentang Rencana Tata Ruang Wilayah, kawasan sempadan sungai, kawasan sepanjang kanan kiri sungai, yang memiliki manfaat penting untuk mempertahankan kelestarian fungsi sungai, maka pemanfaatan garis sempadan sungai ditetapkan untuk sungai tidak bertanggul (sungai kecil) di dalam kawasan perkotaan yang memiliki daerah pengaliran sungai seluas $500 \mathrm{~km} 2$ sekurang-kurangnya 50 meter dihitung dari tepi sungai pada waktu yang ditetapkan.
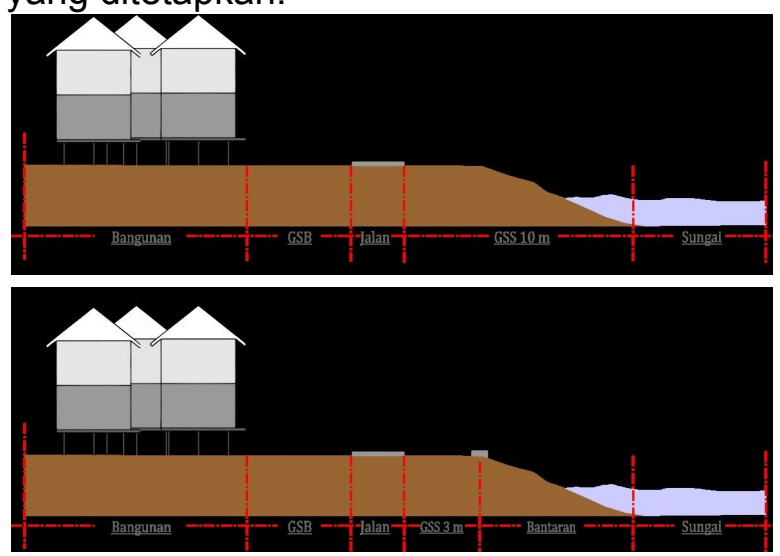

Gambar 3.Sempadan Sungai Bersanggul dan Tidak Bersanggul

Sumber: Diolah oleh penulis berdasarkan Perda Kab.Banjar nomor 3 Tahun 2013

4. Ruang Terbuka Hijau

Berdasarkan Undang-Undang No. 26

Tahun 2007 tentang Penataan Ruang, ruang terbuka hijau adalah area memanjang/jalur dan/atau mengelompok, yang pemanfaatannya bersifat terbuka. Tujuan dan fungsi dari penyediaan ruang terbuka hijau menurut Permen PU No.05/PRT/M/2008, sebagai berikut:

Tujuan

1. Meningkatkan kesesuaian dan keserasian lingkungan di perkotaan sebagai pengaman lingkungan.

2. Menciptakan keseimbangan antara lingkungan alam dan lingkungan binaan untuk kepentingan masyarakat.

3. Menjaga kawasan resapan air perkotaan

Fungsi

1. Fungsi Ekologis (Utama)
- sebagai sistem sirkulasi udara

- Sebagai pengatur iklim mikro

- Sebagai peneduh dan produsen oksigen

- Sebagai habitat satwa

- Sebagai penyerap air hujan, polutan media.

2. Fungsi tambahan

- Sosial budaya, Memberikan gambaran mengenai budaya lokal, dan media komunikasi masyarakat serta tempat rekreasi untuk masyarakat.

- Meningkatkan perekonomian

- Estetika, memberikan kenyamanan, meningkatkan kreativitas dan produktivitas masyarakat, untuk memberikan nilai keindahan arsitektural, menciptakan keserasian dan keseimbangan antara area terbangun dan tidak terbangun.

Ruang terbuka hijau memiliki peran penting dalam memperbaiki kualitas hidup masyarakat. Oleh karena itu, ketersediaan ruang terbuka hijau di perkotaan sangat diperlukan terutama pada kawasan padat penduduk dan kawasan kumuh.

5. Permukiman Kumuh

Berdasarkan UU No. 1 Tahun 2011 tentang Perumahan dan Kawasan Permukiman, permukiman kumuh merupakan permukiman tidak layak huni yang disebabkan adanya ketidakteraturan bangunan dengan kepadatan yang tinggi, serta kualitas bangunan serta sarana dan prasarana yang tidak memenuhi syarat. Berdasarkan definisi di atas, permukiman kumuh merupakan suatu permukiman yang mengalami penurunan kualitas. Peraturan Menteri PUPR Nomor 02/PRT/M/2016 tentang Peningkatan Kualitas Terhadap Perumahan dan Permukiman Kumuh menyebutkan kriteria dan tipologi perumahan dan permukiman kumuh pada Pasal 4 sampai Pasal 14. 


\section{B. Tinjauan Konsep}

\section{Environmental Waterfront}

Konsep environmental waterfront memanfaatkan kawasan tepi perairan dengan mempertahankan lingkungan alami tepian air sebagai ruang terbuka hijau. Minghu Wetland Park merupakan salah satu contoh penerapan environmental dengan menjadikannya sebagai taman lahan basah sebagai infrastruktur ekologis kota dengan beberapa fasilitas ekosistem. Kriteria dalam pokok penataan kawasan tepian sungai sebagai environmental waterfront :

1. Memanfaatkan potensi alam kawasan tepian air sebagai area konservasi dan budaya

2. Memiliki tujuan untuk meningkatkan kesadaran masyarakat dalam melestarikan kekayaan alam tepi air.

3. Memfokuskan penataan pada pada kebersihan badan air dan suplai air bersih.

\section{Recreation Waterfront}

Konsep recreation waterfront bersifat rekreatif dengan memanfaatkan keadaan alami lingkungan kawasan tepi perairan. Bentuk ini dapat berupa : taman dan boathouse. Salah satu contoh penerapan tipe ini berada di Indonesia yaitu Pantai Ancol yang merupakan pantai populer di Indonesia dengan olahraga air dan taman rekreasi Atlantis Water Adventure. Kriteria pokok penataan kawasan tepian sungai sebagai recreation waterfront adalah :

1. Penataan mengikuti arah badan serta aliran air dan memperhatikan keberadaan ruang terbuka.

2. Memanfaatkan kondisi fisik kawasan untuk kegiatan rekreasi.

3. Kegiatan pariwisata perairan ditunjang oleh perbedaan budaya dan geografi.

4. Memanfaatkan arsitektur lokal sebagai daya tarik pengunjung.

\section{Urban Acupuncture}

Urban Acupuncture merupakan sebuah pendekatan yang menjawab masalah sosial perkotaan dan memperbaiki masalah perkotaan. Pendekatan ini diilakukan untuk memberikan solusi penataan agar mendapatkan dampak yang nyata dalam waktu singkat sesuai dengan aturan perencanaan kota yang telah digagas. Urban Acupuncture merupakan penataan skala kecil yang diharapkan mampu memberikan dampak baik dan meningkatkan kualitas yang baik bagi kota. Pendekatan ini menghasilkan reaksi berantai, dengan melakukan penataan 1 (satu) titik yang kemudian dapat menyebar dan memberikan pengaruh terhadap titik lain. Pendekatan Urban Acupuncture memiliki beberapa fokus perhatian dalam perencanaannya (Mujianto, 2015), meliputi :

a) Ruang Terbuka Publik untuk meningkatkan kualitas lingkungan kota

b) Citra kawasan untuk memperkuat ciri khas kota

c) Mixed-Use development

d) TOD, adanya transportasi publik yang baik

e) Warisan Budaya

f) Pemberdayaan masyarakat disesuaikan dengan kebijakan kota.

Urban Acupuncture memiliki prinsip-prinsip sebagai berikut :

1) Tindakan yang dilakukan sederhana

2) Biaya yang dibutuhkan terjangkau

3) Berlaku di setiap situasi

4)Dapat mengatasi kebutuhan yang mendesak

5) Memiliki efek instan

6) Fokus pada target

7) Dapat memfasilitasi kebutuhan warga

8) Cepat tanggap.

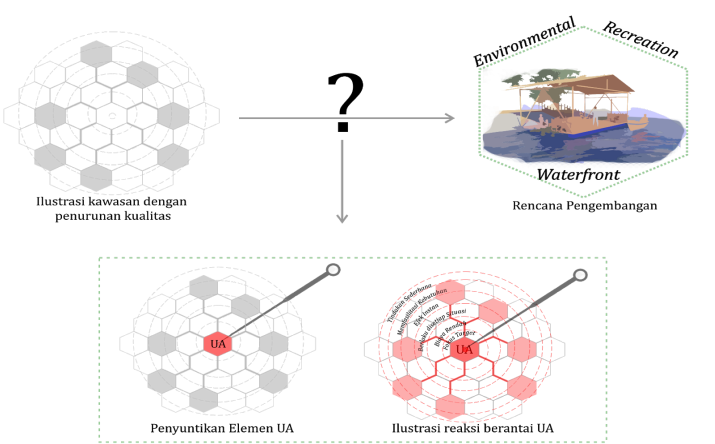

Gambar 3. Prinsip Metode Urban Acupuncture yang diterapkan pada kawasan Sumber: Analisis Penulis (2020) 


\section{PEMBAHASAN}

\section{A. Lokasi}

Desa Murung Kenanga berlokasi di Kecamatan Martapura, Kabupaten Banjar dengan luas wilayah yaitu $1,12 \mathrm{~km}^{2}$, dengan tingkat kepadatan penduduk 2.973 jiwa dan jumlah penduduk \pm 3360 jiwa berdasarkan data statistik BPS tahun 2018. Tapak berlokasi di Jalan Kubah RT 006, tapak mencakup area tepian sungai. Tingkat kepadatan bangunan yang rapat satu sama lain mendukung penting dan perlunya penanganan di kawasan ini untuk meningkatkan kualitas kawasan. Tapak ini dipilih berdasarkan pertimbangan beberapa aspek dibawah ini :

Tabel 1. Pemilihan Tapak

\begin{tabular}{|c|c|c|}
\hline Aspek & $\begin{array}{l}\text { Tapak bagian } \\
\text { Selatan }\end{array}$ & $\begin{array}{c}\text { Tapak bagian } \\
\text { Utara }\end{array}$ \\
\hline View & $\begin{array}{l}\text { Jangkauan lebih } \\
\text { sempit (-) }\end{array}$ & $\begin{array}{l}\text { Jangkauan } \\
\text { view lebih luas } \\
(+)\end{array}$ \\
\hline Potensi & $(-)$ & $\begin{array}{l}\text { Terdapat } \\
\text { tambak milik } \\
\text { warga }(+)\end{array}$ \\
\hline $\begin{array}{l}\text { Fasilitas } \\
\text { penunjan } \\
\mathrm{g}\end{array}$ & Tidak ada (-) & $\begin{array}{l}\text { Terdapat } \\
\text { mushola }(+)\end{array}$ \\
\hline $\begin{array}{l}\text { Aksesibili } \\
\text { tas }\end{array}$ & $\begin{array}{ll}\text { Lebih } & \text { dekat } \\
\text { dengan } & \text { jalan } \\
\text { utama }(+) & \end{array}$ & $\begin{array}{ll}\text { Lebih jauh } & \text { jaun } \\
\text { dengan } & \text { jalan } \\
\text { Utama (-) } & \end{array}$ \\
\hline $\begin{array}{l}\text { Eksisting } \\
\text { tepian }\end{array}$ & $\begin{array}{l}\text { Keseluruhan sisi } \\
\text { tepian ini masih } \\
\text { memiliki area } \\
\text { tanah }(+)\end{array}$ & $\begin{array}{ll}\text { Hanya } 1 / 2 \text { tepian } & \text { yang } \\
\text { masih } \\
\text { memiliki } & \text { area } \\
\text { tanah (-) } & \end{array}$ \\
\hline Sungai & $\begin{array}{l}\text { Karena } \\
\text { merupakan } \\
\text { cabang sungai } \\
\text { sehingga } \\
\text { letaknya lebih } \\
\text { tersembunyi(-) }\end{array}$ & $\begin{array}{l}\text { Lebih sering } \\
\text { dilalui, karena } \\
\text { merupakan } \\
\text { area tepian } \\
\text { sungai } \\
\text { utama(+) }\end{array}$ \\
\hline
\end{tabular}

sumber : Analisis Penulis, 2020
Berdasarkan hasil analisis dari beberapa aspek yang dipertimbangkan diatas maka tapak yang akan dirancang adalah tapak disisi bagian utara dan ujung delta.

\section{B. Konsep Rancangan}

1. Konsep Programatik

Kawasan tepian sungai ini dikembangakan dengan memperhatikan lingkungan sekitar kawasan dengan menjaga fungsi tepian sungai dan lahan rawa yang ada sehingga dapat dijadikan sebagai kawasan rekreasi edukasi keluarga dengan meningkatkan potensi kawasan.

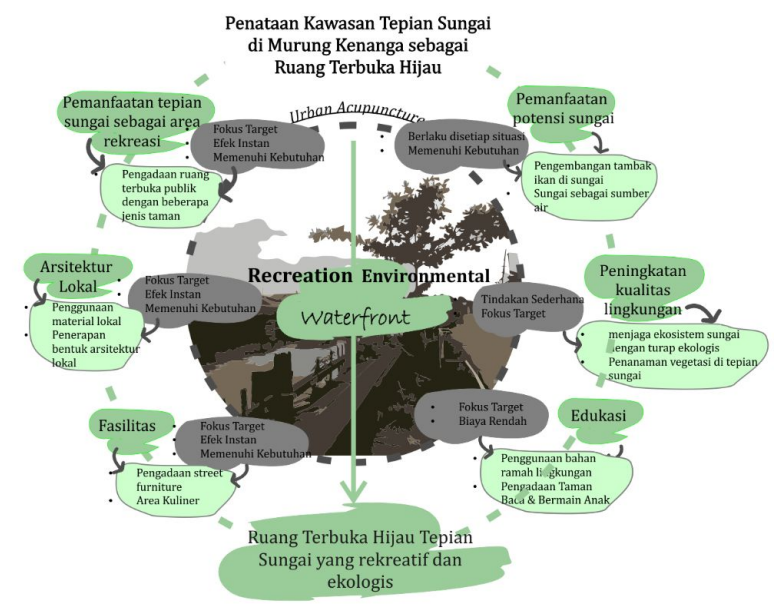

Gambar 8.Konsep Programatik Sumber: Analisis Pribadi (2020)

Penggunaan urban acupuncture dalam pengembangan konsep environmental dan recreation waterfront, memicu munculnya aktivitas positif pada titik-titik rancangan sehingga akan memberikan efek positif kepada lingkungan disekitarnya. Efek positif yang diberikan berupa interaksi antar masyarakat melalui rancangan taman-taman dalam ruang terbuka tepian sungai sehingga masyarakat semakin erat untuk mengembangkan kawasan sehingga menambah kepedulian masyarakat baik lingkungan maupun sosial. 
2. Zoning Tapak dan Bentuk

Kawasan tepian sungai dikembangkan menjadi ruang terbuka hijau tepian sungai yang memperhatikan kondisi lingkungan disekitarnya, dalam hal ini sebagian besar tapak dikembangkan menjadi beberapa jenis taman seperti taman bermain \& baca anak, taman santai, taman olahraga, dan area tambak yang masuk ke dalam zona inti kawasan. Taman yang dirancang merupakan ruang yang dapat dimanfaatkan masyarakat sebagai area rekreasi tepian sungai sehingga memunculkan kembali aktivitas positif di tepian sungai. Zona inti dapat dicapai oleh zona penerima yang terdiri dari gerbang kawasan, area parkir, dan dermaga. Dalam prinsip penerapan konsep recreation waterfront disebutkan bahwa area waterfront yang akan dijadikan tempat rekreasi harus memiliki fasilitas penunjang salah satunya area kuliner, oleh karena itu dalam perancangan ini terdapat zona kuliner yang diletakkan di bagian timur tapak dekat dengan area tambak.

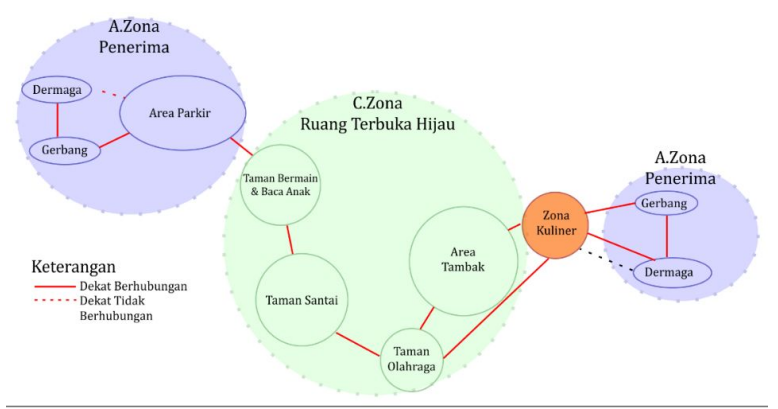

Gambar.Skema Hubungan Ruang

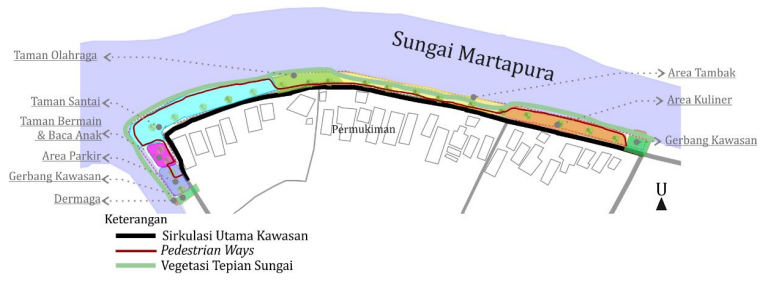

Gambar.Zoning Tapak
Bentuk bangunan mengambil dari tipologi bangunan sekitar sebagai bentuk dasar. Teras rumah yang biasanya digunakan masyarakat sebagai tempat bersantai dan berkumpul bersama menjadi salah satu alasan bentuk ini digunakan bentuk bangunan sederhana dengan material menggunakan kayu sehingga menyatu dengan lingkungan sekitar. Pengambilan bentuk arsitektur lokal ini merupakan salah satu penerapan recreational waterfront dengan menggunakannya sebagai ciri khas. Bagian kaki bangunan dibuat panggung untuk menjaga tanah yang ada di tepian sungai agar tetap dapat bernapas. Memaksimalkan bukaan pada bangunan sehingga view dapat lebih luas dan memperlancar penghawaan. Dalam penerapan metode urban acupuncture terdapat prinsip rancangan berlaku di setiap situasi, dalam hal ini bentukan yang dipilih dirancang dapat digunakan di kemudian hari ketika diperlukan dengan menambahkan area tambahan pada bangunan.

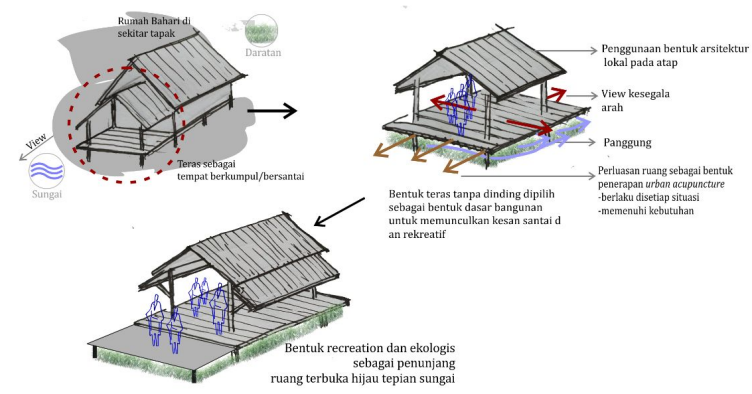

Gambar Konsep Bentuk

3. Sirkulasi dan Parkir

Sirkulasi yang terbentuk pada ruang terbuka hijau tepian sungai ini, memanjang mengikuti alur tepian sungai dan tapak sehingga memiliki bentuk yang dinamis. Sirkulasi pada kawasan ini terbagi menjadi 2 yaitu sirkulasi pejalan kaki di area tapak dan sirkulasi utama tapak berupa jalan 
lingkungan. Pedestrian ways dibentuk mengikuti pola taman didalamnya dan sebagian besar memanfaatkan sisi luar tepian (lebih dekat dengan sungai) sehingga masyarakat memiliki orientasi atau view lebih besar menuju sungai. Sirkulasi utama pada tapak dilengkapi dengan lampu jalan dan pohon sebagai peneduh. Material yang digunakan pada pedestrian ways menggunakan susupan papan kayu yang diambil dari bentuk titian sehingga dapat menyatu dengan kawasan di sekitarnya. Pengunjung dari luar kawasan tidak dapat memasukinya menggunakan motor sehingga harus memarkirkan kendaraannya di area parkir . Area parkir ini diletakkan di bagian barat tapak dekat dengan dermaga dan gerbang kawasan sebagai akses masuk ke kawasan ruang terbuka hijau tepian sungai. Area parkir terbagi menjadi 2 bagian yaitu parkir sepeda dan parkir motor. Pada area parkir sepeda dilengkapi dengan vertical garden dan tempat duduk. Area Parkir mempertahankan tanaman yang ada di area ini sehingga tidak merusak tepian.

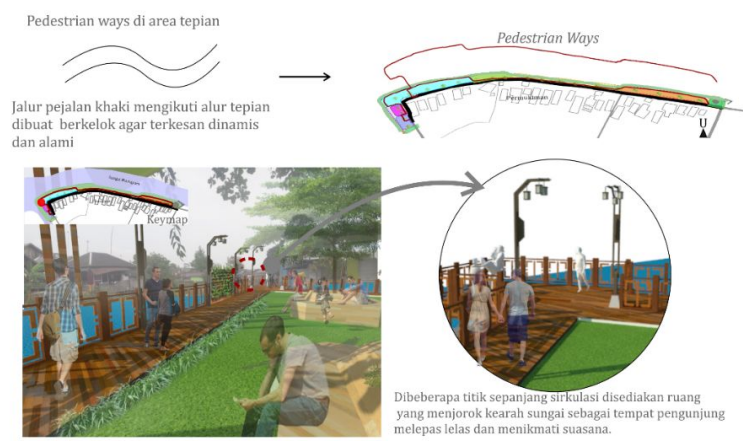

Gambar.Konsep Sirkulasi

4. Penerapan Metode Urban Acupuncture a.Fokus Target, fokus terhadap permasalahan tepian sungai untuk mengembalikan fungsi ekologisnya dgn menggunakan turap ekologis dan penggunaan vegetasi tepian air,sementara untuk wadah bersosialisasinya menjadikan kawasan tepian sungai menjadi taman-taman yang meningkatkan aktivitas seperti adanya penambahan gazebo.
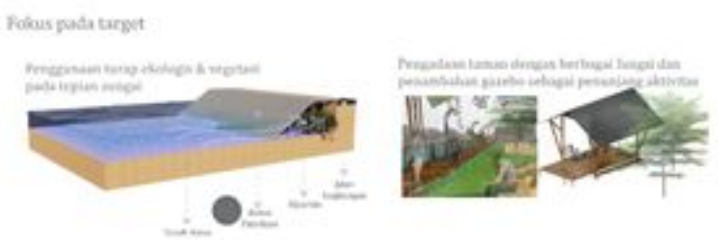

b.Biaya Rendah, dalam rancangan diterapkan dengan penggunaan material lokal dan material bekas contohnya pada pelampung area tambak, dan dermaga yang menggunakan drum bekas sebagai pelampung.

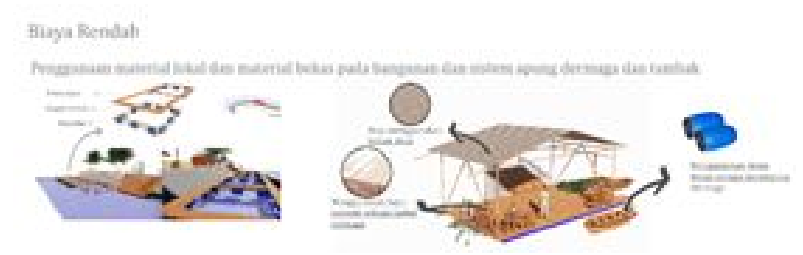

c.Efek Instan, pengadaan ruang terbuka hijau dengan beberapa taman sebagai pemicu aktivitas di dalamnya akan mempengaruhi lingkungan sekitar ruang terbuka hijau.

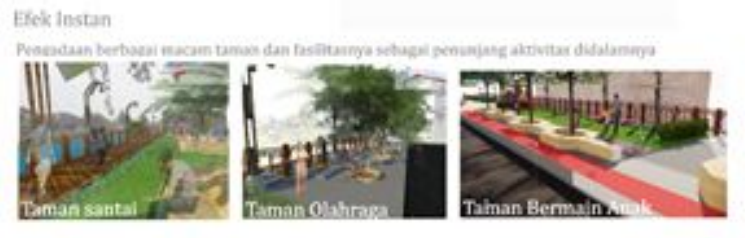

d.Berlaku di setiap situasi,penerapan dalam rancangannya adalah penggunaan sistem konstruksi apung pada dermaga dan warung kuliner sebagai penyesuaian terhadap pasang surut air sungai sehingga dapat tetap digunakan, selain itu pada rancangan gazebo terdapat area lantai gazebo dapat diperluas sehingga dapat menyesuaikan dengan kapasitas pengguna.

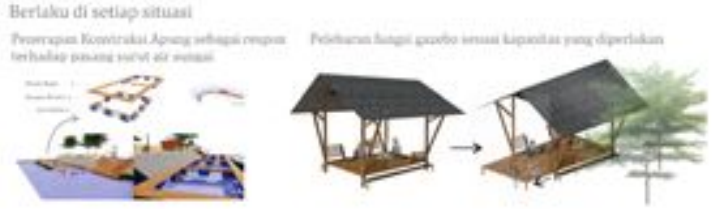


e.Memfasilitasi kebutuhan masyarakat dengan pengadaan jenis taman menyesuaikan kebutuhan masyarakat sekitar seperti taman bermain untuk anak, taman santai sebagai wadah bersosialisasi, dan taman olahraga.
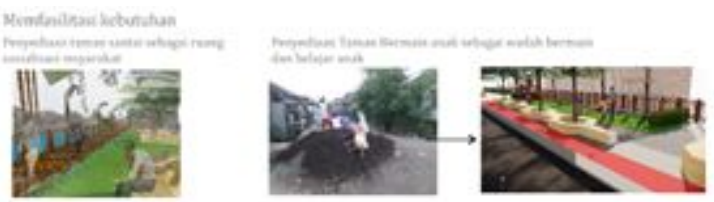

f.Tindakan sederhana, penerapan dalam rancangan adalah penggunaan teknologi sederhana seperti penggunaan struktur bangunan yang sederhana sehingga dalam pemeliharaannya masyarakat tetap dapat memperbaikinya atau memeliharanya secara bergotong royong.

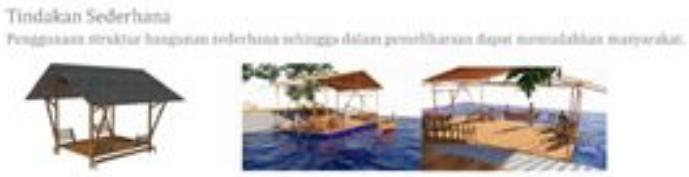

HASIL

Rancangan ini terbagi menjadi 3 zona yaitu zona penerima, zona utama, dan zona komersil. Zona penerima terdiri dari area parkir, gerbang kawasan dan dermaga. Zona utama terdiri dari taman santai, taman bermain anak, dan taman olahraga. Zona Komersil terdiri dari area kuliner apung dan area kuliner di tepian.
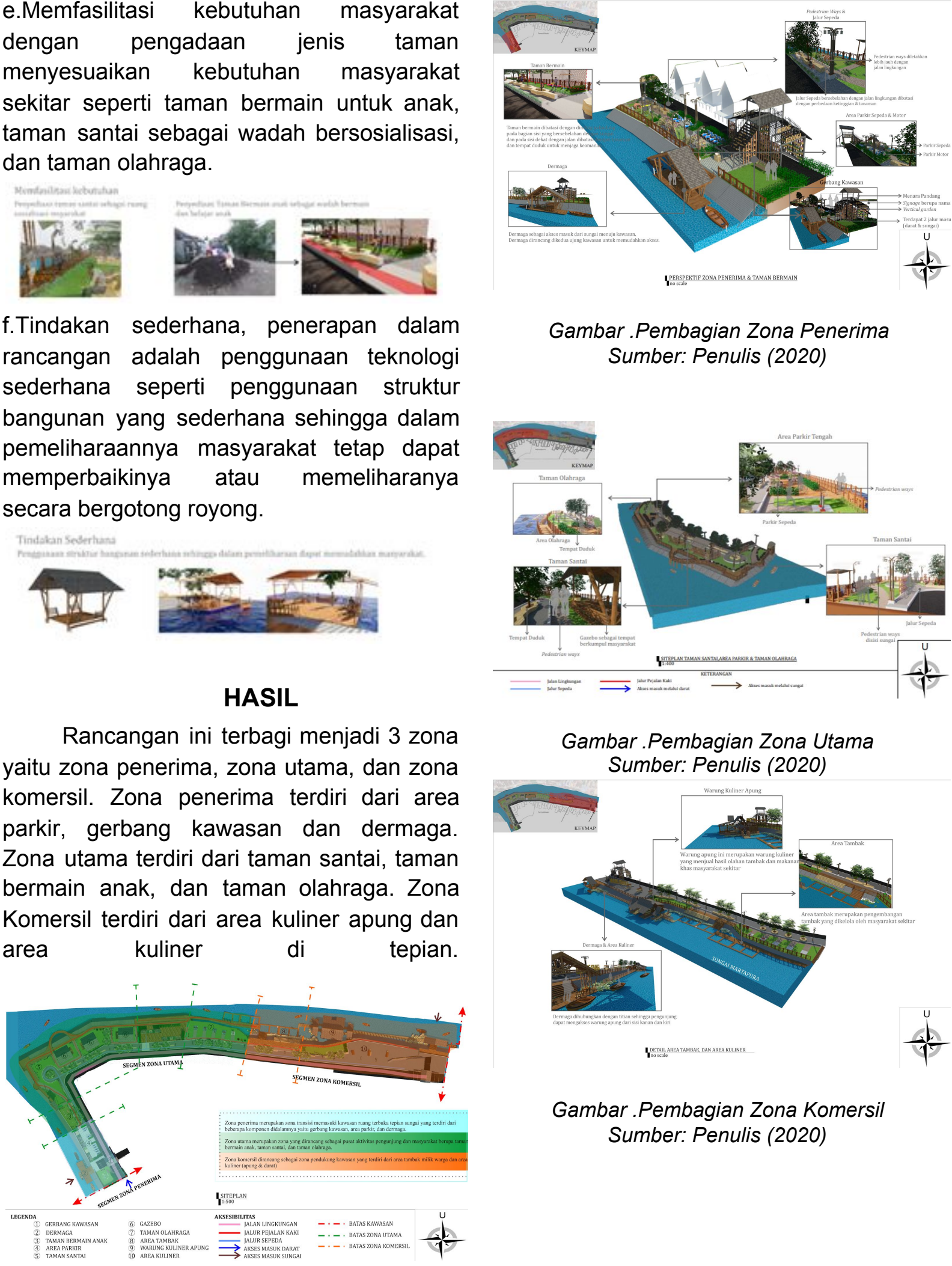

Gambar .Pembagian Zona Penerima Sumber: Penulis (2020)

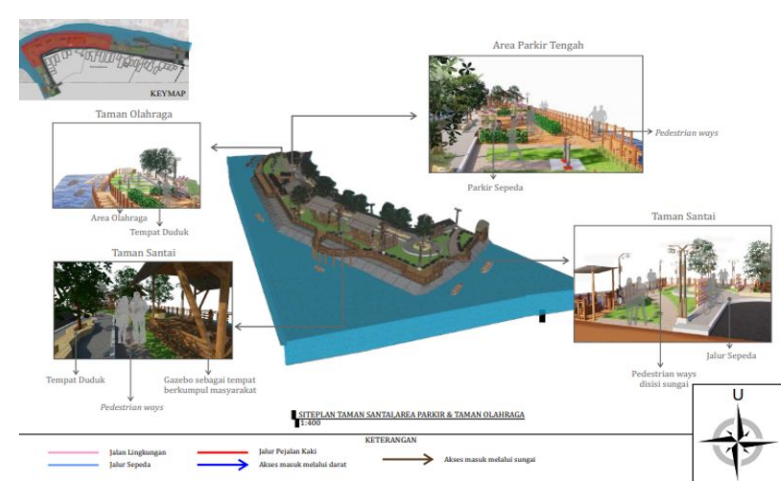

Gambar .Pembagian Zona Utama Sumber: Penulis (2020)

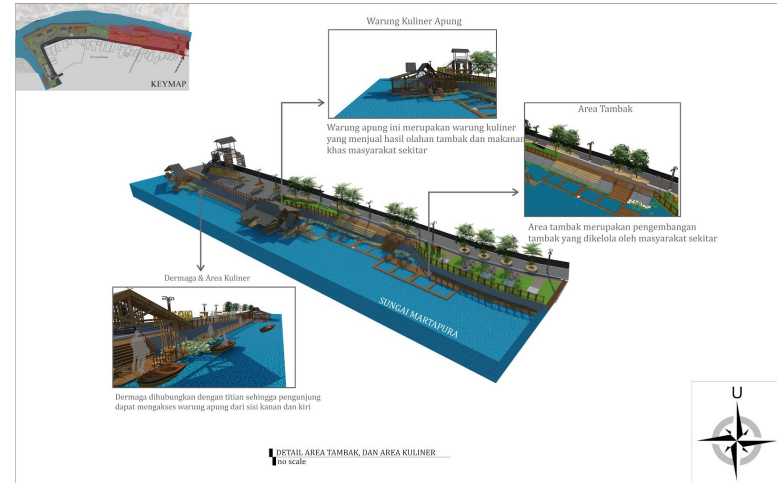

Gambar .Pembagian Zona Komersil Sumber: Penulis (2020)

Gambar .Siteplan

Sumber: Penulis (2020) 

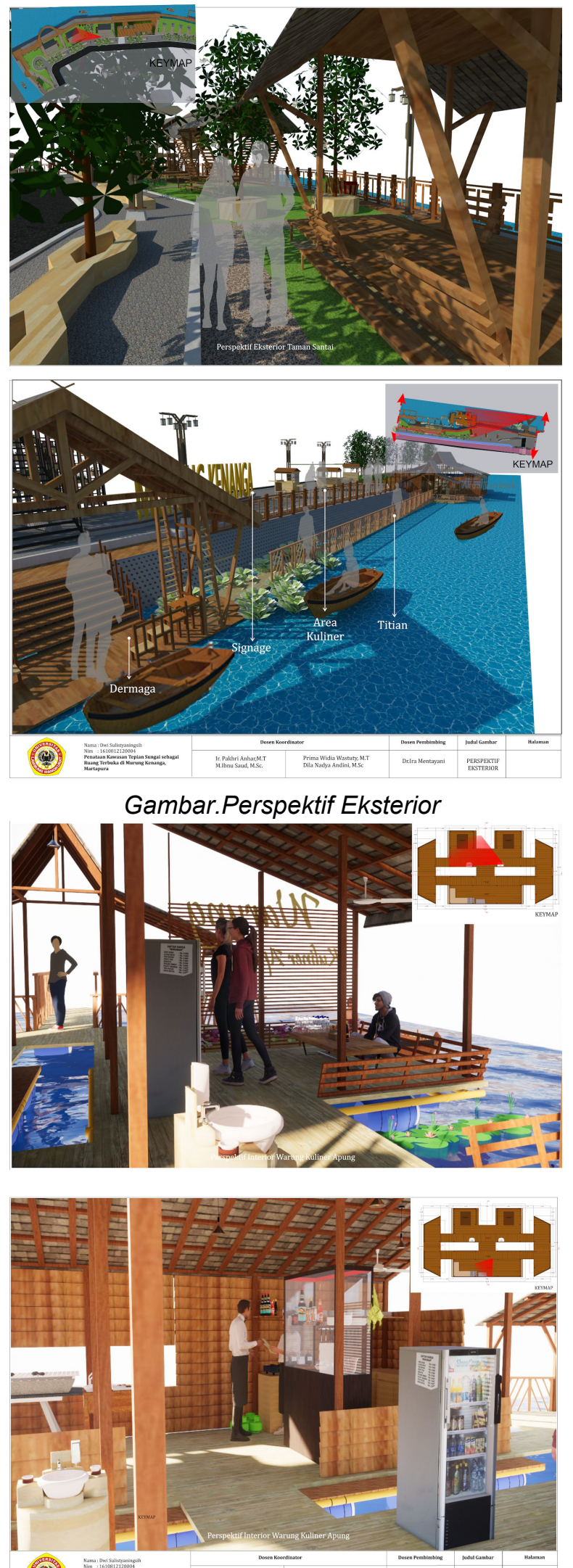

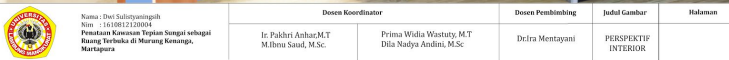

Gambar Perspektif Interior Warung Kuliner Apung Sumber: Penulis (2020)

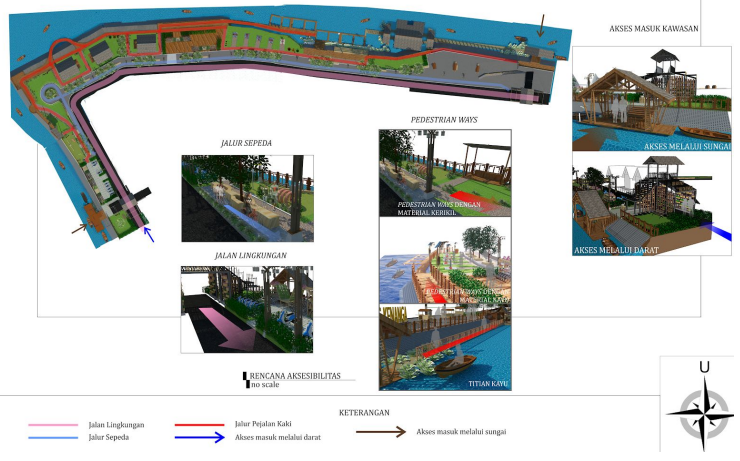

Gambar. Konsep Sirkulasi pada Kawasan

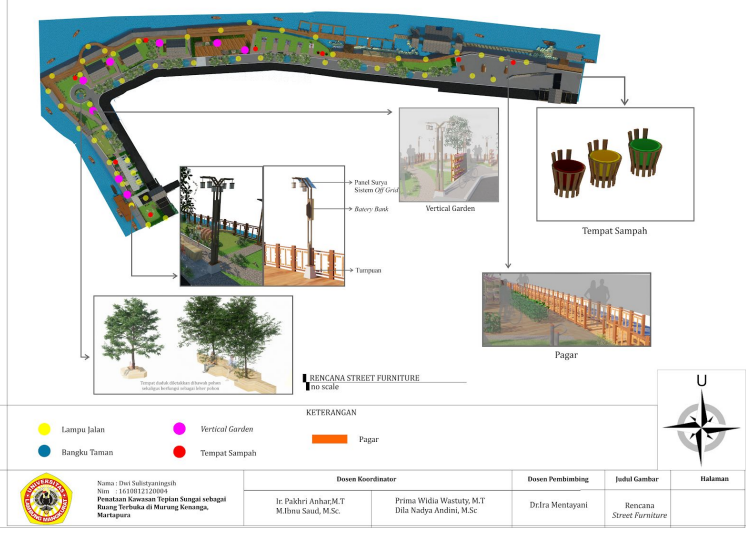

Gambar Penataan Street Furniture pada Kawasan

Sumber: Penulis (2020)

\section{KESIMPULAN}

Penataan kawasan tepian sungai di Murung Kenanga bertujuan menjadikan kawasan tepian sungai sebagai wadah aktivitas masyarakat dalam bersosialisasi dan mengembalikan fungsi ekologis tepian sungai. Upaya yang dilakukan untuk mencapai tujuan tersebut dengan mempertimbangkan beberapa kriteria pengembangan konsep environmental dan recreation waterfront menggunakan prinsip-prinsip urban acupuncture dalam desain agar memudahkan masyarakat dalam melakukan perbaikan kedepannya. 
Penggunaan metode urban acupuncture dipilih dengan menjadikan kawasan tepian sungai di Murung Kenanga sebagai ruang terbuka hijau tepian sungai menjadi titik aktivitas positif masyarakat sekitar. Prinsip penerapan urban acupuncture yang digunakan dalam titik rancangan pada ruang terbuka hijau tepian sungai di Murung Kenanga adalah :

a) Fokus pada target, pengembalian fungsi tepian sungai dengan penggunaan vegetasi dan turap ekologis serta penyediaan ruang terbuka hijau.

b) Biaya rendah, penggunaan material lokal dan material bekas.

c) Berlaku di setiap situasi, ruang-ruang yang terbentuk dapat berkembang sesuai dengan kondisi.

d)Memiliki efek instan, penyediaan ruang ruang aktivitas pada RTH sebagai pemicu aktivitas masyarakat.

e)Dapat memfasilitasi kebutuhan masyarakat, perencanaan ruang ruang yang dapat menjadi wadah masyarakat bersosialisasi.

f) Tindakan sederhana, penggunaan teknologi sederhana sehingga dapat diperbaiki masyarakat secara berkala. Metode menjadi penunjang konsep environmental dan recreation waterfront yang diterapkan dengan menjadikan kawasan tepian sungai sebagai ruang terbuka yang rekreatif dan memperhatikan lingkungan. Penerapan konsep dan metode yang diterapkan bertujuan untuk menjaga fungsi ekologis tepian sungai dan menjadikannya sebagai ruang terbuka hijau melalui, 1) Peningkatan kualitas lingkungan kawasan melalui pemanfaatan potensi alam dan pengembalian fungsi sungai dengan pengembangan area tambak, penggunaan vegetasi tepian sungai dan turap ekologis 2) Pemanfaatan area tepian sungai sebagai area rekreasi dengan perancangan taman bermain dan baca anak, taman santai, taman olahraga, dan area kuliner 3) Pemicu aktivitas positif masyarakat dengan pengadaan ruang terbuka hijau yang dilengkapi dengan fasilitas penunjang aktivitas di dalamnya. Penataan kawasan ini diharapkan dapat menjadikan kawasan tepian sungai di Murung Kenanga menjadi ruang terbuka hijau tepian sungai yang menjadi wadah aktivitas masyarakat sekitar dan pengunjung dengan tetap memperhatikan lingkungan sehingga fungsi ekologis tepian sungai dapat terjaga.

\section{DAFTAR PUSTAKA}

\section{Referensi Buku dan Jurnal}

Annisa. (2014). Ragam Keruangan

Tepi Sungai di Kawasan Permukiman Produktif Alalak, Banjarmasin. 1-15.

Casagrande, M. (2010). Urban Acupuncture. University of Portsmouth

Dina Purnama, P. I. (n.d.). PENATAAN ULANG KAWASAN PERMUKIMAN KUMUH TEPI SUNGAI. Program Studi Arsitektur Universitas Sumatera Utara.

HA, R. (2009). Konsep Drainase di Lahan Rawa. Universitas Lambung Mangkurat, 4-5.

Maulidyanto, A. T. (2014). Mengembalikan Fungsi RTH Taman Lawang, Menteng, Jakarta Pusat dengan UrbanAcupuncture. Teknik Arsitektur, Fakultas Sains \& Teknologi Universitas UIN Maulana Malik Ibrahim.

Mentayani, I. (2019). Identitas dan Eksistensi Permukiman Tepi Sungai di Banjarmasin. Prosiding Seminar Nasional Lingkungan Lahan Basah, Vo.4 No.3.

Merdekari, R. (2017). Kawasan Wisata Sungai Kampung Ketupat. Program Studi Arsitektur Universitas Lambung Mangkurat. 59

Ramadhini, F. E. (2018). Penataan Ruang Terbuka pada Kawasan Teluk 
Kelayan di Banjarmasin. Prodi Arsitektur Universitas Lambung Mangkurat.

Ricgby, A. B. (1996). The New Waterfronts : The World Wide Urban Succes Story. New York: McGraw Hill.

Setianingsih, S. (2015). PENATAAN TEPIAN SUNGAI CENRANAE DENGAN PENDEKATAN EKOLOGIS DI KOTA SENGKANG. National Academic Journal of Architecture.

Tomigolung, B. A. (2018). Penataan Ruang Kawasan Tepi Sungai Tondano di Segmen Kampung Tubir sampai Jembatan Miangas di Manado. Jurnal Spasial Vol 5. No.1 Program Studi PWK Universitas Sam Ratulangi.

Tsukio, Y. (1984). The Significance of Contemporary Waterfront Development. Journal of Process Architecture, No.52, 10-14.

Wikantiyoso, R. (2010). Pemanfaatan dan Perancangan Kawasan Tepi Air Sungai Terpadu dan Berkelanjutan. I(2), 13.

Wreen, D. (1983). Urban Waterfront Development. Washington: Urban Land Inst. Sumber berdasarkan Kebijakan

Pemerintah : UU No.1 Tahun 2011 tentang Perumahan \& Kawasan

Permukiman Permen PUPR Nomor 02/PRT/M/2016

Peraturan Daerah kabupaten Banjar tentang Rencana Tata Ruang Wilayah Nomor 3 Tahun 2013

Website

Anonim. (2019). Monterey Bay Aquarium. Retrieved from Tripadvisor: https://www.tripadvisor.com/Attraction_Revie w-g32737-d104804-ReviewsMonterey Bay Aquarium

Boston Planning \& Development Agency. (2020). Retrieved from South Boston Waterfront: http://www.bostonplans.org/planning/climate- changeenvironmental-planning/south-boston -waterfront

Climate Change \& Environmental Planning, South Boston Waterfront. (2020). Retrieved from Bostonplans.org: http://www.bostonplans.org/planning/climatechangeenvironmental-planning/south-boston -waterfront

Expedia. (2020). Inner Harbor Baltimore. Retrieved from Expedia.co.id: https://www.expedia.co.id/Marina-Pelabuhan -Baltimore-Inner-DowntownBaltimore.d6162 $\underline{880}$.

Ghifari, A. Z. (2018, April 18). 573,04 Ha Kawasan Kumuh Kabupaten Banjar di 32 Titik, Tersebar 12 Kecamatan-36 Desa. Retrieved from Kanal Kalimantan: https://www.kanalkalimantan.com/57304-hakawasan-kumuh-kabupatenbanjar-di-32-titiktersebar-12-kecamatan-36-desal

Hamzens, W. P. (2013, November 22). Penyuluhan Pembangunan. Retrieved from Penataan Kawasan:

http://penyuluhanpembangunan.blogspot.co

m/2013/11/prinsip-dasarpenataan-kawasanpenataan.html

Mujianto, E. (2015, Maret 28). Teori Arsitektur Kota. Retrieved from DokumenTips:

https://dokumen.tips/documents/teori-arsitekt ur-kota.html

PUPR, K. (2019, Januari 30). Restorasi Sungai Cikapundung Upaya Penataan Kawasan Sempadan Sungai. Retrieved from Direktorat Jenderal Sumber Daya Air Kementerian Pekerjaan Umum dan Perumahan rakyat: http://sda.pu.go.id/pages/posts/Restorasi-Su ngai-Cikapundung-UpayaPenataan-Kawasa n-Sempadan-Sungai

South Boston Waterfront. (2020). Retrieved from Boston Planning \& development agency: http://www.bostonplans.org/planning/climate- 
change-environmentalplanning/south-boston -waterfront

Tamasya Fauzian, R. (2018, Juli 31). Revitalisasi Kota Tua Kisah from Zero to Hero Sungai Cheonggyecheon. Retrieved from medcom.id:

https://www.medcom.id/properti/news-proper ti/akW3ePMk-kisah-from-zeroto-hero-sungai -cheonggyecheon

Torre, A. L. (1989). Waterfront Development. New York: Van Nostrand Reinhold. Tripadvisor. (2019). Monterey Bay Aquarium. Retrieved from Tripadvisor: https://www.tripadvisor.com/Attraction_Revie w-g32737-d104804-ReviewsMonterey_Bay Aquarium-Monterey Monterey County Calif ornia.html

Turenscape. (2015, Januari 21). Minghu Wetland Park / Turenscape. Retrieved from Archdaily: https://www.archdaily.com/590066/minghu-w etland-parkturenscape 